\title{
microRNA-221 and microRNA-18a
}

identification in stool as potential biomarkers for the non-invasive diagnosis of colorectal carcinoma

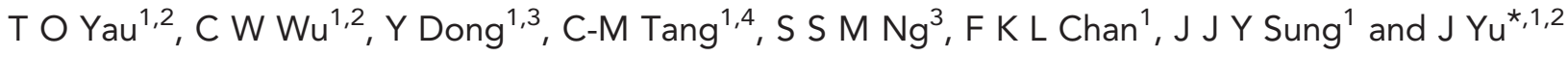 \\ ${ }^{1}$ Institute of Digestive Disease and Department of Medicine and Therapeutics, State Key Laboratory of Digestive Disease, Li Ka \\ Shing Institute of Health Sciences, The Chinese University of Hong Kong, Hong Kong, China; ${ }^{2}$ Gastrointestinal Cancer Biology \& \\ Therapeutics Laboratory, Shenzhen Research Institute, The Chinese University of Hong Kong, Shenzhen, China; ${ }^{3}$ Department of \\ Surgery, The Chinese University of Hong Kong, Hong Kong, China and ${ }^{4}$ Department of Pharmacology, University of Oxford, \\ Oxford OX1 3QT, UK
}

Background: The detection of microRNA (miRNA) dysregulation in stool is a novel approach for the diagnosis of colorectal carcinoma (CRC). The aim of this study is to investigate the use of miR-221 and miR-18a in stool samples as non-invasive biomarkers for CRC diagnosis.

Methods: A miRNA expression array containing 667 miRNAs was performed to identify miRNA dysregulation in CRC tissues. We focused on miR-221 and miR-18a, two significantly upregulated miRNAs which were subsequently verified in 40 pairs of CRC tissues and 595 stool samples (198 CRCs, 199 polyps and 198 normal controls).

Results: miR-221 and miR-18a were upregulated in the miRNA expression array. miR-221 and miR-18a levels were also significantly higher in 40 CRC tumours compared with their respective adjacent normal tissues. In stool samples, miR-221 and miR-18a showed a significant increasing trend from normal controls to late stages of CRC $(P<0.0001)$. The levels of stool miR-221 and miR-18a were both significantly higher in subjects with stages I+ II (miR-221: $P<0.0001$, miR-18a: $P<0.0001)$ and stages III + IV of CRC (miR-221: $P=0.0004$, miR-18a: $P<0.0001)$ compared with normal controls. The AUC of stool miR-221 and miR-18a were 0.73 and 0.67 for CRC patients as compared with normal controls, respectively. No significant differences in stool miR-221 and miR-18a levels were found between patients with proximal and distal CRCs. The use of antibiotics did not influence stool miRNA-221 and miRNA-18a levels.

Conclusions: Stool-based miR-221 can be used as a non-invasive biomarker for the detection of CRC.

Colorectal carcinoma (CRC) is the third most common cancer, and the fourth highest cause of cancer-related mortality worldwide, with an estimated incidence of one million cases annually (Jemal et al, 2011). More significantly, the latest report from the Hong Kong Cancer Registry in 2011 identified CRC as the leading cause of cancer-related morbidity in Hong Kong. The pathogenesis of
CRC follows a stepwise progression from benign adenomas to malignant adenocarcinomas and distant metastasis. Survival is thus inversely related to cancer stages, with up to $90 \%$ of deaths preventable if detected early. Colorectal carcinoma, however, is often asymptomatic in its early stages and remains undiagnosed until advanced stages, where prognosis becomes poor. Thus, there

*Correspondence: Professor J Yu; Email: junyu@cuhk.edu.hk

Received 21 April 2014; revised 6 August 2014; accepted 8 August 2014; published online 18 September 2014

(c) 2014 Cancer Research UK. All rights reserved 0007-0920/14 
Table 1. Clinicopathological characteristics of recruited subjects

\begin{tabular}{|c|c|c|c|c|}
\hline Category & Normal & Adenoma & AA & CRC \\
\hline No. of cases & 198 & 151 & 48 & 198 \\
\hline Age at enrolment, years (mean \pm s.d.) & $58.65 \pm 6.87$ & $60.39 \pm 5.65$ & $58.73 \pm 6.78$ & $66.53 \pm 11.05$ \\
\hline \multicolumn{5}{|l|}{ Gender, no. (\%) } \\
\hline $\begin{array}{l}\text { Male } \\
\text { Female }\end{array}$ & $\begin{array}{r}84(42 \%) \\
114(58 \%)\end{array}$ & $\begin{array}{l}83(55 \%) \\
68(45 \%)\end{array}$ & $\begin{array}{l}31(65 \%) \\
17(35 \%)\end{array}$ & $\begin{array}{r}116(59 \%) \\
82(41 \%)\end{array}$ \\
\hline \multicolumn{5}{|l|}{ Locationa $^{\mathrm{a}}$, no. (\%) } \\
\hline $\begin{array}{l}\text { Proximal } \\
\text { Distal (excluding rectum) } \\
\text { Rectum } \\
\text { Others }{ }^{\text {b }}\end{array}$ & & & $\begin{aligned} & 20(41.7 \%) \\
& 18(37.5 \%) \\
& 8(16.6 \%) \\
& 2(4.2 \%)\end{aligned}$ & $\begin{array}{c}50(25.3 \%) \\
82(41.4 \%) \\
66(33.3 \%) \\
0\end{array}$ \\
\hline \multicolumn{5}{|l|}{ CRC staging } \\
\hline $\begin{array}{l}\text { I+II } \\
I I I+I V \\
\text { Unknown }\end{array}$ & & & & $\begin{array}{c}106(53.5 \%) \\
88(44.5 \%) \\
4(2.0 \%)\end{array}$ \\
\hline \multicolumn{5}{|l|}{ Antibiotic intake, no. (\%) } \\
\hline $\begin{array}{l}\text { Yes } \\
\text { No }\end{array}$ & & & & $\begin{array}{r}26(13 \%) \\
172(87 \%)\end{array}$ \\
\hline \multicolumn{5}{|c|}{$\begin{array}{l}\text { Abbreviations: } \mathrm{AA}=\text { advanced adenoma; } \mathrm{CRC}=\text { colorectal carcinoma. } \\
\text { a Colorectal neoplasms were classified by three locations: proximal colon (caecum, ascending, hepatic flexure, and transverse), distal colon (splenic flexure, descending, sigmoid, and recto- } \\
\text { sigmoid junction) and rectum. }\end{array}$} \\
\hline
\end{tabular}

is a compelling need to identify molecular biomarkers for mass screening and early diagnosis of CRC (Wu et al, 2012, 2014).

The advent of microRNA (miRNA) detection techniques has created a new focus in cancer biomarker research. MicroRNAs belong to a class of highly conserved short single-stranded segments (18-25 nucleotides) of non-coding ribonucleic acid, which induce messenger RNA degradation and/or inhibit translation of target genes via binding to the $3^{\prime}$-untranslated regions to regulate gene expression. Due to the unique clinicopathological features of cancer cells, miRNA expression profiles also vary from normal cell types (Ahmed et al, 2009; Chang et al, 2011). The two miRNA biomarkers (miR-221 and miR-18a) identified in this study have a well-established link with colon tumorigenesis. miR221 belongs to the miR-221/222 family located on Xp11.3. It is a known suppressor of the p27 protein-a key regulator of the cell cycle. In support of its role in tumorigenesis, downregulation of p27 by miR-221 has been shown to induce cell proliferation and reduce apoptosis in multiple cancers including prostate (Galardi et al, 2007), glioblastoma (Gillies and Lorimer, 2007), hepatic (Pineau et al, 2010) and gastric carcinoma (Chun-Zhi et al, 2010). The oncogenic KRAS also induces increased expression of miR-221 in CRC cell lines (Tsunoda et al, 2011). miR-18a belongs to the miR-17-92 cluster located in the 13q31.1 region, an area partly regulated by the oncogenic transcription factor c-Myc (O'Donnell et al, 2005). The oncogenic role of the miR-17-92 cluster has also been well-documented, with its overexpression linked to accelerated tumour growth, cell proliferation and progression from benign adenomas to CRC (Hayashita et al, 2005; He et al, 2005; Diosdado et al, 2009).

The aim of this study was to evaluate two upregulated stool miRNAs (miR-221 and miR-18a) as non-invasive CRC diagnostic biomarkers. These two candidate miRNA biomarkers were validated in 40 pairs of primary CRC tumours, and then in a large cohort of 595 stool samples containing 198 CRCs, 199 adenomas and 198 healthy subjects. Through this large casecontrolled study, we identified and characterised stool-based miR-221 as a potential biological marker for the diagnosis of CRC.

\section{MATERIALS AND METHODS}

Patients and sample collection. Forty pairs of CRC and adjacent normal tissue specimens (at least $4 \mathrm{~cm}$ away from the tumour margin) were biopsied during the initial colonoscopy or during the surgical resection. Tissue specimens were snap frozen immediately in a liquid nitrogen filled vacuum flask and stored at $-80^{\circ} \mathrm{C}$.

Stool samples were collected from 595 subjects (198 CRCs, 199 adenomas and 198 healthy subjects; Table 1) using a $30 \mathrm{ml}$ disposable stool sample container with screw cap. The containers were manufactured under aseptic conditions to eliminate any biological contamination. Stool samples from CRC patients were collected 7 days after colonoscopy, whereas stool samples from healthy controls and adenoma patients were collected before bowel purgation and colonoscopy. Following collection, all stool samples were immediately stored at $4{ }^{\circ} \mathrm{C}$, and transferred to a $-80^{\circ} \mathrm{C}$ freezer within $24 \mathrm{~h}$.

Advanced adenoma was defined as an adenoma $\geqslant 10 \mathrm{~mm}$ in diameter with villous, tubullovillous features or high-grade dysplasia (Winawer et al, 1993; Zarchy and Ershoff, 1994). Colorectal neoplasms were classified by three locations as follows: the proximal colon (caecum, ascending, hepatic flexure and transverse), distal colon (splenic flexure, descending, sigmoid and recto-sigmoid junction) and rectum. Exclusion criteria included subjects with a family history of familial adenomatous polyposis or hereditary non-polyposis CRC, previous colonic surgery or adjuvant therapy for CRC before surgery. Patients who were 
passing type 7 stool on the Bristol Stool Chart (Lewis and Heaton, 1997) were also excluded. All participants had signed informed consent for obtaining stool and tissue specimens, and were recruited from Alice Ho Miu Ling Nethersole Hospital, Tai Po, Hong Kong and Prince of Wales Hospital, The Chinese University of Hong Kong, Hong Kong. The study protocol was approved by the institutional review board of the Hong Kong Hospital Authority and The Chinese University of Hong Kong.

MicroRNA extraction in tissue and stool specimens. Frozen colon tissue $(10-20 \mu \mathrm{g})$ was added into $500 \mu \mathrm{l}$ of Trizol reagent (Invitrogen, Carlsbad, CA, USA) in a $1.5 \mathrm{ml}$ RNase-free Microfuge tube. The tissue was homogenised by RNase-free pestles and vortexed for $30 \mathrm{~s}$ to allow for complete homogenisation. Chloroform $(100 \mu \mathrm{l})$ was subsequently added to the $1.5 \mathrm{ml}$ tube. Fresh human stool samples $(10-20 \mathrm{~g})$ were collected using $30 \mathrm{ml}$ specimen containers and stored at $-80^{\circ} \mathrm{C}$. The stool sample (200-300 mg (wet weight)) was scooped from the container and added into $1 \mathrm{ml}$ of Trizol LS reagent (Invitrogen) in a $2 \mathrm{ml}$ RNase-free microcentrifuge tube (Invitrogen). The stool sample was subsequently deformed by a RNase-free pestle (USA Scientific, Woodland, CA, USA) and homogenised by a vortex mixer in the Trizol LS reagent. After completing the homogenisation, $200 \mu \mathrm{l}$ of chloroform was added into the $2 \mathrm{ml}$ tube. Total stool RNA, including miRNA, was extracted from the Trizol LS-chloroform mixture using the miRNeasy Mini Kit (Qiagen, Valencia, CA, USA) as per the protocol provided. Total RNA was eluted in $50 \mu \mathrm{l}$ of nuclease free water. RNA concentration was measured by Nanodrop 2000 (Thermo Fisher Scientific, Wilmington, DE, USA). Each total RNA sample was normalised to $2 \mathrm{ng}_{\mu \mathrm{l}}^{-1}$ based on the Nanodrop 2000 reading.

Reverse transcription (RT) for microRNA microarray. Reverse transcription for the miRNA microarray was carried out using Megaplex Primer pools, Human Pools A and B v2.1 (Applied Biosystems, Foster City, CA, USA). The cDNA product was subsequently used to perform the miRNA array. In the array, the miRNA profile of 667 human miRNAs in the tumour tissues and their adjacent normal tissues of five patients was obtained using TaqMan Human MicroRNA Array Set v2.0 (Applied Biosystems). Briefly, $6 \mu$ l of Megaplex RT product was added to $444 \mu$ l nucleasefree water and $450 \mu \mathrm{l}$ TaqMan Universal PCR Master Mix with no AmpErase UNG (Applied Biosystems). Reaction mix (100 $\mu \mathrm{l})$ was loaded into each of the eight fill reservoirs of the array. The array was then centrifuged to distribute the cDNA samples to the reaction wells. Real-time quantitative PCR was performed using Applied Biosystems 7900HT Real-Time PCR System. PCR profile was as follows: $95^{\circ} \mathrm{C}$ for $10 \mathrm{~min}$, and then 50 cycles of $95^{\circ} \mathrm{C}$ for $15 \mathrm{~s}$ and $60^{\circ} \mathrm{C}$ for $1 \mathrm{~min}$. Data collection was carried out at the $60^{\circ} \mathrm{C}$ step. Results were analysed by the SDS RQ Manager 1.2 software (Applied Biosystems).

MicroRNA quantitation by quantitative real-time PCR. Quantitative real-time PCR of each miRNA was performed using the TaqMan miRNA reverse transcription Kit (Applied Biosystems) and TaqMan Human miRNA Assay (miR-18a: 002422 and miR221: 002279). In brief, $0.3 \mu \mathrm{l}$ TaqMan miRNA reverse transcription primer, $3 \mathrm{~nm}$ dNTP (with dTTP), 10 units reverse transcriptase, 0.6 units RNase inhibitor, $0.3 \mu \mathrm{l} 10 \times$ RT buffer, and 2 ng total RNA were used in one $\mathrm{RT}$ reaction with a total volume of $3 \mu \mathrm{l}$. The thermal cycling conditions were as follows: $16^{\circ} \mathrm{C}$ for $30 \mathrm{~min}, 42^{\circ} \mathrm{C}$ for $30 \mathrm{~min}, 85^{\circ} \mathrm{C}$ for $5 \mathrm{~min}$, and hold at $4{ }^{\circ} \mathrm{C}$. The reverse transcription product was subsequently diluted four-fold by adding $9 \mu \mathrm{l}$ of nuclease free water.

The PCR reaction mix contains $10 \mu \mathrm{l}$ TaqMan Universal PCR Master Mix with no AmpErase UNG, $0.5 \mu \mathrm{l}$ miRNA TaqMan primers, $4 \mu \mathrm{l}$ diluted RT product and $5.5 \mu \mathrm{l}$ nuclease free water. Real-time PCR was carried out using the 7500 real-time PCR system (Applied Biosystems). The PCR profile was as follows: $95^{\circ} \mathrm{C}$ for $10 \mathrm{~min}$, followed by 50 cycles of $95^{\circ} \mathrm{C}$ for $15 \mathrm{~s}$ and $60^{\circ} \mathrm{C}$ for $1 \mathrm{~min}$. Data collection was carried out at each $60^{\circ} \mathrm{C}$ step. The quantitation of the two target miRNAs (miR-221 and miR-18a) were based on standard curves plotted by known input among all of the miRNAs, and normalised to per nanogram of the total input RNA. Based on standard curves plotted from known amounts of synthetic miR-221 and miR-18a individually, a technical detection limit of two copies for miR-221 would give a Ct value of 42 , and a technical detection limit of five copies for miR-18a would give a $\mathrm{Ct}$ value of 47 . Consequently, we assigned ' 0 ' to all Ct values $>42$ for miR-221, and 47 for miR-18a. Samples with no amplification of miR-221 or miR-18a were included and also assigned a value of ' 0 ' in the analysis, provided the sample could be amplified by another miRNA such as miR-135b or miR-20a (Wu, et al, 2014). All assays were performed in a blinded manner.

Statistics. The difference between miRNA expression in paired CRC and adjacent normal tissue specimens was evaluated by the Wilcoxon matched-pairs test. Receiver operating characteristic (ROC) curves were generated based on the stool miRNA levels of $\mathrm{CRC}$ and control groups. Significance in trend was tested by the Jonckheere trend test. Differences in stool miRNA levels between groups were analysed by the unpaired Student's $t$-test. Two cutoff values were selected using ROC curves for reference, based on either a high sensitivity or a high specificity. Combination analysis was calculated by binary logistic regression. $P<0.05$ was taken as statistically significant. The Jonckheere trend test and ROC analysis were done by SPSS 16.0 (SPSS Inc., Chicago, IL, USA). All other statistical tests were done by Graphpad Prism 5.01 (Graphpad Software Inc., San Diego, CA, USA).

\section{RESULTS}

miR-221 and miR-18a are significantly upregulated in primary CRC compared with their adjacent normal tissues. In addition to miR-135b and miR-31 (Wu et al, 2014), miR-221 and miR-18a were found to be two of the most upregulated miRNAs in the miRNA expression array. Thus miR-221 and miR-18a were selected for validation in 40 paired tumour and adjacent normal tissues from CRC patients. We found that miR-221 (1.96-fold, $P<0.0001)$ and miR-18a (2.65-fold, $P=0.0003)$ expression were significantly upregulated in tumours compared with their respective adjacent normal tissues (Table 2).

Stool miR-221 and miR-18a are potential non-invasive biomarkers for CRC. miR-221 and miR-18a were examined in stool samples from CRC and adenoma patients. Patients were stratified based on their histological stages, with individuals assigned to the groups normal colonoscopy $(n=198)$, adenoma $(n=151)$, advanced adenoma $(n=48)$, CRC stages I + II $(n=106)$ and CRC stages III + IV $(n=88)$ (Table 1$)$. As shown in Figure 1, levels of stool miR-221 (Figure 1A) as well as miR-18a (Figure 1B)

\begin{tabular}{|c|c|c|c|}
\hline \multicolumn{4}{|c|}{$\begin{array}{l}\text { Table 2. miRNAs are differentially expressed in } \\
\text { tissues compared with adjacent normal tissues }\end{array}$} \\
\hline miRNA & $\begin{array}{c}\text { Percentage of } \\
\text { samples with } \\
\text { elevated expression }\end{array}$ & $\begin{array}{l}\text { Fold change } \\
\text { (interquartile } \\
\text { range) }\end{array}$ & $P$-value ${ }^{a}$ \\
\hline miR-221 & $77.5 \%(31 / 40)$ & $1.96(1.025-3.319)$ & $<0.0001$ \\
\hline miR-18a & $77.5 \%(31 / 40)$ & $2.65(1.078-6.828)$ & 0.0003 \\
\hline \multicolumn{4}{|c|}{$\begin{array}{l}\text { Abbreviation: miRNA, microRNA. } \\
{ }^{a} P \text {-values were analysed by Wilcoxon matched-pairs test. }\end{array}$} \\
\hline
\end{tabular}



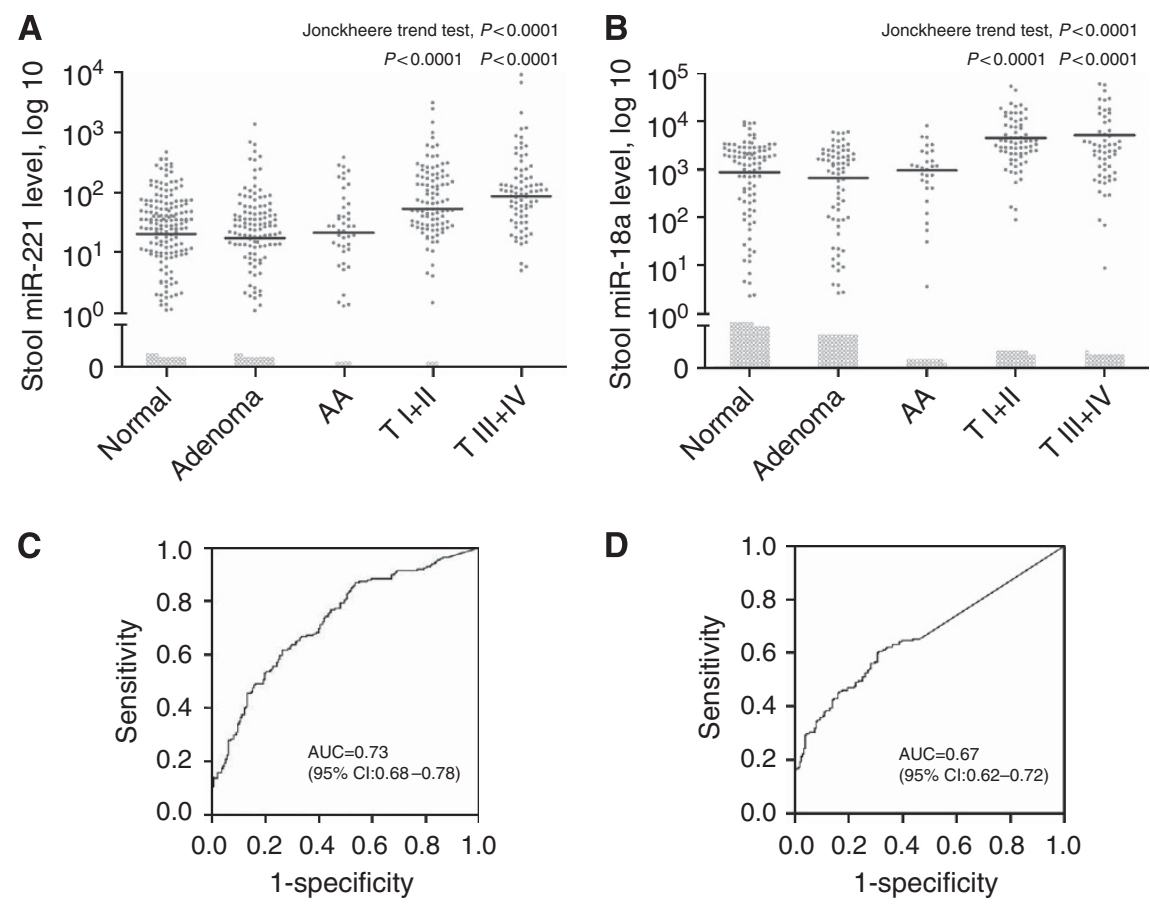

Figure 1. Levels of candidate markers in stool (A) miR-221 and (B) miR-18a, and their respective receiver operating characteristic (ROC) curves (C) miR-221 and (D) miR-18a. Patients were categorised into four groups: individuals with a normal colonoscopy (normal) ( $n=124)$, adenoma $(n=72)$, advanced adenoma (AN) $(n=48)$, CRC stages I + II $(T 1,2)(n=24)$ and CRC stages III + IV $(T 3,4)(n=76)$. The miRNA levels were expressed as the number of copies per nanogram of extracted RNA. Open circles represent samples with an undetectable miRNA level. The lines denote the medians. $P<0.05$ denotes statistical significance. ROC curves were plotted to discriminate all CRC patients from individuals with normal colonoscopy findings.

displayed a significant trend of increase with lesion stages $(P<0.0001)$. The two miRNAs were able to discriminate patients with CRC from healthy individuals. Stool miR-221 was significantly higher in CRC stages I + II (mean: 187.8, 95\% CI: 105.6-270.0, $P<0.0001$ ) and in CRC stages III + IV (mean: 360.6, 95\% CI: 100.6-620.6, $P=0.0004)$ compared with healthy controls (mean: 47.0, 95\% CI: 36.3-57.8) (Figure 1A). Stool miR-18a was also significantly increased in CRC stages I + II (mean: 4504, 95\% CI: 2919-6088, $P<0.0001$ ) and CRC stages III + IV (mean: 5131, 95\% CI: 2749-7513, $P<0.0001$ ) as compared with controls (mean: 872, 95\% CI: 633-1111) (Figure 1B).

The area under the curve (AUC) values were 0.73 (95\% CI: $0.68-0.78$ ) and 0.67 (95\% CI: 0.62-0.72) for miR-221 (Figure 1C) and miR-18a (Figure 1D) in the detection of CRC, respectively. The cutoff values for stool miR-221 and miR-18a were selected to maximise the sum of the sensitivity and specificity, and were 48 copies per ng and 446 copies per ng of extracted stool RNA, respectively. miR-221 has a sensitivity of $62 \%$ and specificity of $74 \%$, whereas miR-18a has a sensitivity of $61 \%$ and specificity of $69 \%$. The levels of miR-221 and miR-18a were correlated. Sixtyeight per cent of samples with upregulated miR-221 (cutoff: 48) also had upregulated miR-18a (cutoff: 446). Combining miR-221 and miR-18a produced an AUC of 0.75 , with a sensitivity of $66 \%$ and specificity of $75 \%$ for CRC. Two relatively high specificity levels $(80 \%$ and $90 \%)$ were chosen to reflect its performance for reference, with the cutoff values of 68 and 128 copies per ng for miR-221, demonstrating a sensitivity of $52 \%$ and $35 \%$, respectively. The cutoff values of 1845 and 2886 copies per ng for miR-18a had a sensitivity of $46 \%$ and $35 \%$, respectively (Table 3 ).

Stool miR-221 and miR-18a are not associated with the location of CRC. We evaluated the sensitivities of stool miR-221 and miR18 a based on the location of CRC. No significant differences were observed in sensitivities for these two miRNAs in detecting CRCs from the proximal colon, distal colon and the rectum. miR-221 showed a higher sensitivity in detecting rectal lesions than carcinomas situated in the proximal or distal colon, but not at a statistically significant level $(P=0.058)$ (Figure 2$)$.

Stool miR-221 and miR-18a expressions are not associated with antibiotic intake. We investigated the effects of antibiotic intake on stool miR-221 and miR-18a. Twenty-six CRC patients had taken antibiotics within 1 month of stool collection, whereas the remaining $162 \mathrm{CRC}$ patients had not. There were no significant differences in stool miR-221 and miR-18a expression between the groups with or without antibiotic intake (Figure 3 ).

\section{DISCUSSION}

Detecting aberrantly expressed miRNA in stool has emerged as a promising non-invasive approach to CRC screening (Ahmed et al, 2009; Koga et al, 2010; Link et al, 2010; Wu et al, 2012). Stool miRNAs demonstrate high stability and can be detected with high reproducibility by real-time PCR (Wu et al, 2012). Since CRC exhibits recognisable early stages and has high homogeneity in miRNA alterations (Luo et al, 2011), stool miRNA may be a useful non-invasive tool for CRC screening. We have previously investigated the expression profile of 667 miRNAs in a microarray, and reported miR-135b and miR-31 as potential biomarkers ( $\mathrm{Wu}$ et al, 2014). In this study, miR-221 and miR-18a were verified in 40 paired tumour and adjacent normal tissues from CRC patients. Both miRNAs were confirmed to be more highly expressed in tumours than in the adjacent normal tissue (Table 2). We then investigated the expression of miR-221 and miR-18a in stool samples from 595 subjects, including 198 patients with CRC, 199 patients with polyps and 198 individuals with normal colonoscopy (Table 1). The two biomarkers were significantly upregulated in CRC stages I + II (miR-221: $P<0.0001$ and miR-18a: $P<0.0001)$ and CRC stages III + IV (miR-221: $P=0.0004$ and miR-18a: 


\begin{tabular}{|c|c|c|c|c|c|c|}
\hline Stool-based microRNA & \multicolumn{3}{|c|}{ microRNA-221 } & \multicolumn{3}{|c|}{ microRNA-18a } \\
\hline Cutoff value ${ }^{a}$ & 48 (best) & 68 (80\% specificity) & 128 (90\% specificity) & 446 (best) & 1845 (80\% specificity) & 2886 (90\% specificity) \\
\hline \multicolumn{7}{|l|}{ Sensitivities, \% (95\% Cl) } \\
\hline CRC & $62(55-68)$ & $52(45-59)$ & $35(28-42)$ & $61(53-68)$ & $46(39-54)$ & $35(29-42)$ \\
\hline \multicolumn{7}{|l|}{ Stage } \\
\hline $\begin{array}{l}I+I I \\
I I I+I V\end{array}$ & $\begin{array}{l}44(33-53) \\
63(52-74)\end{array}$ & $\begin{array}{l}29(20-40) \\
54(42-65)\end{array}$ & $\begin{array}{c}15(8-26) \\
28(19-39)\end{array}$ & $\begin{array}{l}61(54-71) \\
58(47-68)\end{array}$ & $\begin{array}{l}49(39-59) \\
40(30-51)\end{array}$ & $\begin{array}{l}37(28-27) \\
31(21-41)\end{array}$ \\
\hline \multicolumn{7}{|l|}{ Location } \\
\hline $\begin{array}{l}\text { Proximal } \\
\text { Distal } \\
\text { Rectum }\end{array}$ & $\begin{array}{l}49(35-63) \\
63(52-74) \\
70(57-84)\end{array}$ & $\begin{array}{l}41(28-58) \\
57(46-69) \\
55(42-67)\end{array}$ & $\begin{array}{l}29(18-44) \\
35(25-47) \\
38(26-51)\end{array}$ & $\begin{array}{l}62(47-75) \\
59(47-69) \\
62(49-74)\end{array}$ & $\begin{array}{l}46(32-61) \\
46(35-58) \\
48(36-61)\end{array}$ & $\begin{array}{l}36(23-51) \\
37(26-48) \\
33(22-46)\end{array}$ \\
\hline \multicolumn{7}{|l|}{ Antibiotic intake } \\
\hline $\begin{array}{l}\text { Yes } \\
\text { No }\end{array}$ & $\begin{array}{l}65(44-83) \\
61(53-68)\end{array}$ & $\begin{array}{l}58(37-77) \\
51(43-59)\end{array}$ & $\begin{array}{l}33(26-41) \\
46(27-67)\end{array}$ & $\begin{array}{l}62(55-70) \\
50(30-70)\end{array}$ & $\begin{array}{l}48(40-55) \\
38(20-59)\end{array}$ & $\begin{array}{l}35(17-56) \\
35(28-43)\end{array}$ \\
\hline Specificity, \% (95\% CI) & $74(67-80)$ & $80(74-86)$ & 90 (85-94) & $69(62-75)$ & $80(74-86)$ & $90(85-94)$ \\
\hline
\end{tabular}
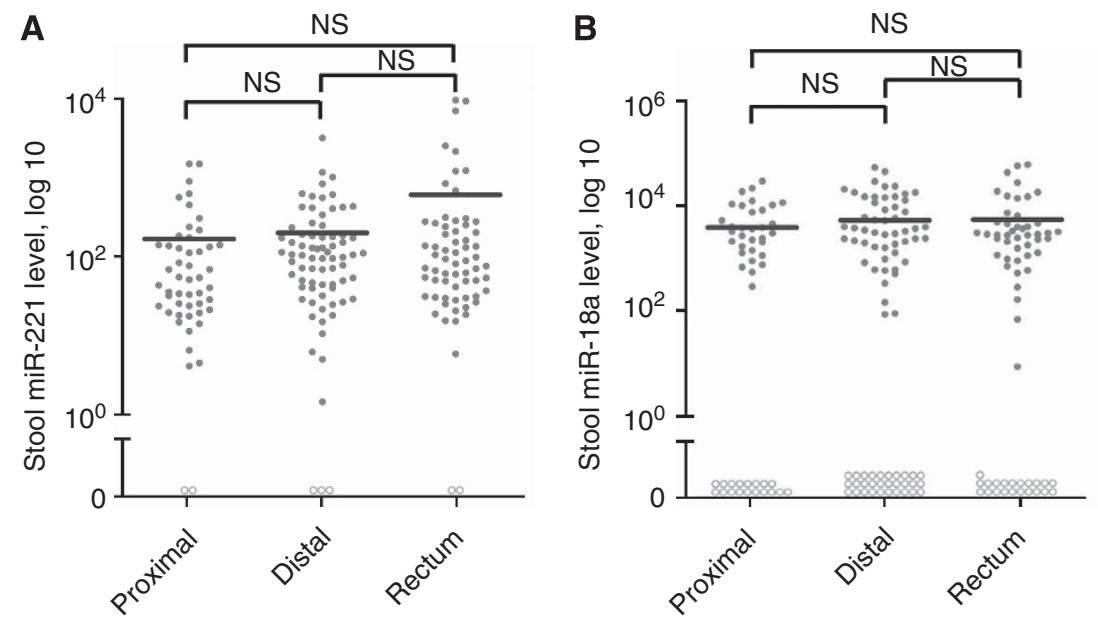

Figure 2. Based on lesion location, colorectal carcinoma (CRC) patients (A) miR-221 and (B) miR-18a were categorised into proximal $(n=50)$, distal $(n=82)$ and rectum $(n=66)$. Colorectal neoplasms were classified by three locations as follows: the proximal colon (caecum, ascending, hepatic flexure and transverse), distal colon (splenic flexure, descending and sigmoid and recto-sigmoid junction) and rectum. NS denotes no statistical significance. miRNA levels were expressed in number of copies per nanogram of extracted RNA. Open circles represent samples with an undetectable miRNA level. The lines denote the medians.

$P<0.0001$, Figure 1) compared with controls. There was no significant upregulation in adenoma or advanced adenoma for both miR-221 and miR-18a. This may be because miR-221 and miR-18a are not upregulated until more advanced stages of CRC. Collectively, these results suggest that the candidate miRNAs regulate key signalling pathways in colorectal tumorigenesis. Thus there is a strong rationale for using them as CRC biomarkers.

Our results revealed that stool miR-221 is a potential diagnostic biomarker. Plasma miR-221 was also previously investigated as a biomarker in CRC diagnosis. While it had a high sensitivity of $86 \%$, it had a poor specificity of $41 \%$ and an AUC of only 0.61 (95\% CI: 0.49-0.72) (Pu et al, 2010). By contrast, stool miR-221 had an AUC of 0.73 , a sensitivity of $62 \%$ and a specificity of $74 \%$. Hence the detection of miR-221 in stool is more specific to CRC than in plasma. This is because plasma miR-221 levels are influenced by other factors such as digestive disease malignancies (Komatsu et al, 2011; Song et al, 2012; Cai et al, 2013; Kawaguchi et al, 2013), reproductive malignancies (Yaman Agaoglu et al, 2011; Hong et al, 2013) and haematological malignancies (Huang et al, 2012; Gimenes-Teixeira et al, 2013), as well as systemic diseases such as atherosclerosis, stroke (Tsai et al, 2013) and obesity (Ortega et al, 2013). In this study, levels of miR-221 have comparable efficacy for the detection of both proximal and distal CRC. Moreover, this stool-based detection method avoids the need for bowel preparation and invasive practice. Therefore, miR-221 is a potential non-invasive diagnostic biomarker for CRC.

Levels of stool miR-18a were also increased in CRC. However, the relatively low AUC value of 0.67 in detection of CRC suggested that miR-18a alone may not be a good biomarker for CRC. Instead, miR-18a may be used in combination with miR-221 to produce an 

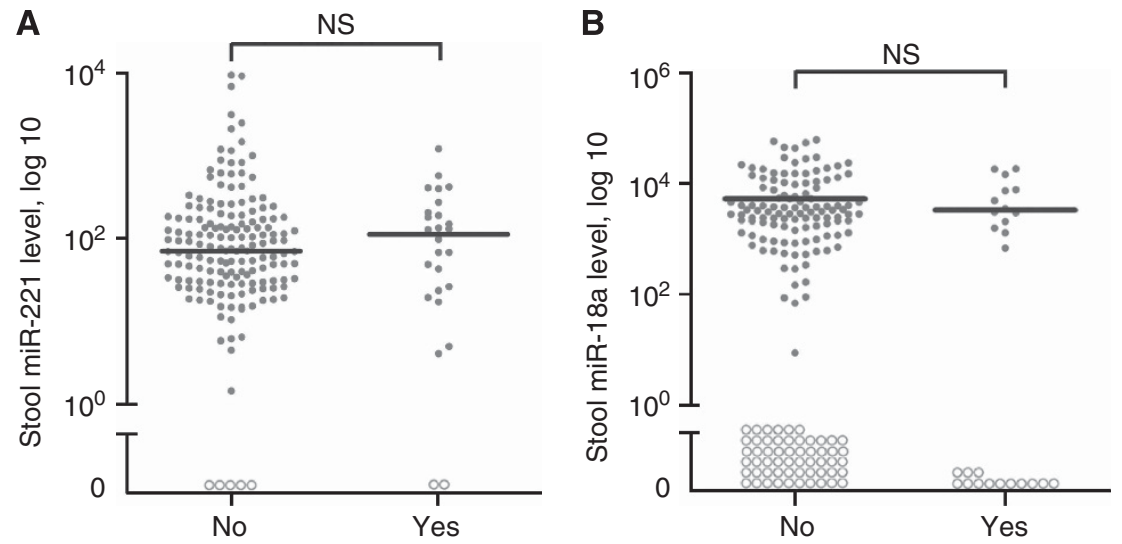

Figure 3. Evaluation of the effects of antibiotics on stool biomarkers (A) miR-221 and (B) miR-18a. Patients who took antibiotics within 30 days of specimen collection $(n=26)$ were compared with patients without any antibiotic intake $(n=162)$. miRNA levels were expressed in number of copies per nanogram of extracted RNA. Open circles represent samples with an undetectable miRNA level. The lines denote the medians.

AUC of 0.75 (95\% CI: 0.70-0.80) (Supplementary Figure 1), with a sensitivity and specificity of $66 \%$ and $75 \%$ for CRC, respectively (Supplementary Table 1). This is better than either marker when considered alone. Therefore, combining miR-18a and/or miR-221 with other stool miRNA biomarkers, such as miR-135b (Wu et al, 2014), may also increase the sensitivity and specificity of CRC detection in screening programs (Supplementary Figure 1) (Supplementary Table 1).

Recent studies have also revealed that the gut microbiome influences miRNA levels (Yang et al, 2013) within host cells. Therefore, we investigated the effects of antibiotics on stool miRNA levels by comparing patients who took antibiotics within 30 days of the stool collection and those who had not. There were no significant differences in stool miR-221 and miR-18a expressions between the groups. To our knowledge, we are the first to report that antibiotic intake by patients does not affect or inhibit microRNA detection in stool (Figure 3). However, further studies are needed to determine the effects of antibiotics on the stool-based miRNAs reported by other groups. Nevertheless, this evidence is significant since antibiotic use is common. Thus restrictions to antibiotic use prior to testing are not required to optimise test performance.

Previously, stool miR-144* was reported as a potential biomarker for CRC detection, with an AUC of 0.83 , sensitivity of $74 \%$ and specificity of $85 \%$ (Kalimutho et al, 2011). The small sample size (35 CRCs and 40 healthy controls) on stool-based miR-144* detection, however, undermines its use as a biomarker in CRC. More recently, stool miR-106a was identified as a molecular marker for identifying CRC patients from those with negative immunochemical faecal occult blood test results (Koga et al, 2013). However, their study was compromised by the use of miR-24 as an internal control. miR-24 belongs to the miR-17-92 cluster, which is known to be upregulated in CRC tissues. It is unclear why such abnormality at tissue level did not translate into a measureable difference in stool in their study, and this requires further investigation (Koga et al, 2013). From a more practical perspective, miR-221 also had greater amplification efficiency than miR-92a (Wu et al, 2012) and miR-135b (Wu et al, 2014), making it highly applicable to CRC screening. To our knowledge, this study tested the largest number of samples to date. Our findings add to an increasingly vast amount of knowledge about the use of stool miRNAs as tools in the non-invasive diagnosis of CRC.

Nevertheless, there are some limitations to this study. All patients were recruited from only two centres and some patients were symptomatic. While we did not detect any significant difference in stool miRNA expression when patients were divided into asymptomatic or symptomatic surgical cohorts, results may not accurately reflect the screening setting in the community.
The small sample sizes of advanced adenoma $(n=48)$ and antibiotic intake groups $(n=26)$ may have also caused bias in our study. Prompted by these findings, larger scale validation across multiple centres and different populations will be conducted.

In conclusion, our study demonstrated that stool-based miR221 can be utilised as a potential biological marker. Its use in combination with other reported miRNA biomarkers can be an effective way of increasing the diagnostic accuracy of CRC screening.

\section{ACKNOWLEDGEMENTS}

We thank Mr Thomas Lam, Ms Joyce Choi and Ms Whitney Tang for their assistance in collecting clinical samples, and Dr JY Shen for his help in statistics. This project was supported by the Shenzhen Technology and Innovation Project Fund, Shenzhen (JSGG20130412171021059), the China 863 programme (2012AA02A506), the China 973 Programme (2013CB531401), the ITF fund Hong Kong (Project code: ITS/276/11), the Shenzhen Municipal Science and Technology R\&D fund (JCYJ JCYJ20120619152326450) and the Shenzhen Virtual University Park Support Scheme to CUHK Shenzhen Research Institute.

\section{CONFLICT OF INTEREST}

The authors declare no conflict of interest.

\section{REFERENCES}

Ahmed FE, Jeffries CD, Vos PW, Flake G, Nuovo GJ, Sinar DR, Naziri W, Marcuard SP (2009) Diagnostic microRNA markers for screening sporadic human colon cancer and active ulcerative colitis in stool and tissue. Cancer Genomics Proteomics 6: 281-295.

Cai H, Yuan Y, Hao Y-F, Guo T-K, Wei X, Zhang Y-M (2013) Plasma microRNAs serve as novel potential biomarkers for early detection of gastric cancer. Med Oncol 30: 452.

Chang KH, Miller N, Kheirelseid EAH, Lemetre C, Ball GR, Smith MJ, Regan M, McAnena OJ, Kerin MJ (2011) MicroRNA signature analysis in colorectal cancer: identification of expression profiles in stage II tumors associated with aggressive disease. Int $J$ Colorectal Dis 26: $1415-1422$.

Chun-Zhi Z, Lei H, An-Ling Z, Yan-Chao F, Xiao Y, Guang-Xiu W, Zhi-Fan J, Pei-Yu P, Qing-Yu Z, Chun-Sheng K (2010) MicroRNA-221 and microRNA-222 regulate gastric carcinoma cell proliferation and radioresistance by targeting PTEN. BMC Cancer 10: 367. 
Diosdado B, van de Wiel MA, Terhaar Sive Droste JS, Mongera S, Postma C, Meijerink WJHJ, Carvalho B, Meijer GA (2009) MiR-17-92 cluster is associated with 13q gain and c-myc expression during colorectal adenoma to adenocarcinoma progression. Br J Cancer 101: 707-714.

Galardi S, Mercatelli N, Giorda E, Massalini S, Frajese GV, Ciafrè SA, Farace MG (2007) miR-221 and miR-222 expression affects the proliferation potential of human prostate carcinoma cell lines by targeting p27Kip1. J Biol Chem 282: 23716-23724.

Gillies JK, Lorimer IAJ (2007) Regulation of p27 Kip1 by miRNA 221/222 in Glioblastoma. Cell Cycle 6: 2005-2009.

Gimenes-Teixeira HL, Lucena-Araujo AR, Dos Santos GA, Zanette DL, Scheucher PS, Oliveira LC, Dalmazzo LF, Silva-Júnior WA, Falcão RP, Rego EM (2013) Increased expression of miR-221 is associated with shorter overall survival in T-cell acute lymphoid leukemia. Exp Hematol Oncol 2: 10.

Hayashita Y, Osada H, Tatematsu Y, Yamada H, Yanagisawa K, Tomida S, Yatabe Y, Kawahara K, Sekido Y, Takahashi T (2005) A polycistronic microRNA cluster, miR-17-92, is overexpressed in human lung cancers and enhances cell proliferation. Cancer Res 65: 9628-9632.

He L, Thomson JM, Hemann MT, Hernando-Monge E, Mu D, Goodson S, Powers S, Cordon-Cardo C, Lowe SW, Hannon GJ, Hammond SM (2005) A microRNA polycistron as a potential human oncogene. Nature 435 : 828-833.

Hong F, Li Y, Xu Y, Zhu L (2013) Prognostic significance of serum microRNA-221 expression in human epithelial ovarian cancer. J Int Med Res 41: 64-71.

Huang J, Yu J, Li J, Liu Y, Zhong R (2012) Circulating microRNA expression is associated with genetic subtype and survival of multiple myeloma. Med Oncol 29: 2402-2428.

Jemal A, Bray F, Center MM, Ferlay J, Ward E, Forman D (2011) Global cancer statistics. CA Cancer J Clin 61: 69-90.

Kalimutho M, Del Vecchio Blanco G, Di Cecilia S, Sileri P, Cretella M, Pallone F, Federici G, Bernardini S (2011) Differential expression of miR-144* as a novel fecal-based diagnostic marker for colorectal cancer. J Gastroenterol 46: 1391-1402.

Kawaguchi T, Komatsu S, Ichikawa D, Morimura R, Tsujiura M, Konishi H, Takeshita H, Nagata H, Arita T, Hirajima S, Shiozaki A, Ikoma H, Okamoto K, Ochiai T, Taniguchi H, Otsuji E (2013) Clinical impact of circulating miR-221 in plasma of patients with pancreatic cancer. Br J Cancer 108: 361-369.

Koga Y, Yasunaga M, Takahashi A, Kuroda J, Moriya Y, Akasu T, Fujita S, Yamamoto S, Baba H, Matsumura Y (2010) MicroRNA expression profiling of exfoliated colonocytes isolated from feces for colorectal cancer screening. Cancer Prev Res 3: 1435-1442.

Koga Y, Yamazaki N, Yamamoto Y, Yamamoto S, Saito N, Kakugawa Y, Otake Y, Matsumoto M, Matsumura Y (2013) Fecal miR-106a is a useful marker for colorectal cancer patients with false-negative results in immunochemical fecal occult blood test. Cancer Epidemiol Biomarkers Prev 22: 1844-1852.

Komatsu S, Ichikawa D, Takeshita H, Tsujiura M, Morimura R, Nagata H, Kosuga T, Iitaka D, Konishi H, Shiozaki A, Fujiwara H, Okamoto K, Otsuji E (2011) Circulating microRNAs in plasma of patients with oesophageal squamous cell carcinoma. Br J Cancer 105: 104-111.

Lewis SJ, Heaton KW (1997) Stool form scale as a useful guide to intestinal transit time. Scand J Gastroenterol 32: 920-924.

Link A, Balaguer F, Shen Y, Nagasaka T, Lozano JJ, Boland CR, Goel A (2010) Fecal MicroRNAs as novel biomarkers for colon cancer screening. Cancer Epidemiol Biomarkers Prev 19: 1766-1774.
Luo X, Burwinkel B, Tao S, Brenner H (2011) MicroRNA signatures: novel biomarker for colorectal cancer? Cancer Epidemiol Biomarkers Prev 20: 1272-1286

O’Donnell KA, Wentzel EA, Zeller KI, Dang CV, Mendell JT (2005) c-Myc-regulated microRNAs modulate E2F1 expression. Nature 435: 839-843.

Ortega FJ, Mercader JM, Catalán V, Moreno-Navarrete JM, Pueyo N, Sabater M, Gómez-Ambrosi J, Anglada R, Fernández-Formoso JA, Ricart W, Frühbeck G, Fernández-Real JM (2013) Targeting the circulating microRNA signature of obesity. Clin Chem 59: 781-792.

Pineau P, Volinia S, McJunkin K, Marchio A, Battiston C, Terris B, Mazzaferro V, Lowe SW, Croce CM, Dejean A (2010) miR-221 overexpression contributes to liver tumorigenesis. Proc Natl Acad Sci USA 107: 264-269.

$\mathrm{Pu}$ X, Huang G, Guo H, Guo C, Li H, Ye S, Ling S, Jiang L, Tian Y, Lin T (2010) Circulating miR-221 directly amplified from plasma is a potential diagnostic and prognostic marker of colorectal cancer and is correlated with p53 expression. J Gastroenterol Hepatol 25: 1674-1680.

Song M, Pan K, Su H, Zhang L, Ma J, Li J, Yuasa Y, Kang D, Kim YS, You W (2012) Identification of serum microRNAs as novel non-invasive biomarkers for early detection of gastric cancer. PLoS One 7: e33608.

Tsai P-C, Liao Y-C, Wang Y-S, Lin H-F, Lin R-T, Juo S-HH (2013) Serum microRNA-21 and microRNA-221 as potential biomarkers for cerebrovascular disease. J Vasc Res 50: 346-354.

Tsunoda T, Takashima Y, Yoshida Y, Doi K, Tanaka Y, Fujimoto T, Machida T, Ota T, Koyanagi M, Kuroki M, Sasazuki T, Shirasawa S (2011) Oncogenic KRAS regulates miR-200c and miR-221/222 in a 3D-specific manner in colorectal cancer cells. Anticancer Res 31: 2453-2459.

Winawer SJ, Zauber AG, O'Brien MJ, Ho MN, Gottlieb L, Sternberg SS, Waye JD, Bond J, Schapiro M, Stewart ET (1993) Randomized comparison of surveillance intervals after colonoscopic removal of newly diagnosed adenomatous polyps. The National Polyp Study Workgroup. N Engl J Med 328: 901-906.

Wu CW, Ng SC, Dong Y, Tian L, Ng SS, Leung WW, Law WT, Yau TO, Chan FK, Sung JJ, Yu J (2014) Identification of microRNA-135b in stool as a potential non-invasive biomarker for colorectal cancer and adenoma. Clin Cancer Res 20: 2994-3002.

Wu CW, Ng SSM, Dong YJ, Ng SC, Leung WW, Lee CW, Wong YN, Chan FKL, Yu J, Sung JJY (2012) Detection of miR-92a and miR-21 in stool samples as potential screening biomarkers for colorectal cancer and polyps. Gut 61: 739-745.

Yaman Agaoglu F, Kovancilar M, Dizdar Y, Darendeliler E, Holdenrieder S, Dalay N, Gezer U (2011) Investigation of miR-21, miR-141, and miR-221 in blood circulation of patients with prostate cancer. Tumour Biol 32: 583-588.

Yang T, Owen JL, Lightfoot YL, Kladde MP, Mohamadzadeh M (2013) Microbiota impact on the epigenetic regulation of colorectal cancer. Trends Mol Med 19: 714-725.

Zarchy TM, Ershoff D (1994) Do characteristics of adenomas on flexible sigmoidoscopy predict advanced lesions on baseline colonoscopy? Gastroenterology 106: 1501-1504.

This work is published under the standard license to publish agreement. After 12 months the work will become freely available and the license terms will switch to a Creative Commons AttributionNonCommercial-Share Alike 3.0 Unported License.

Supplementary Information accompanies this paper on British Journal of Cancer website (http://www.nature.com/bjc) 